\title{
CONSTRUÇÕES CAUSATIVAS SINTÉTICAS: UMA ANÁLISE COMPARATIVA ENTRE A GRAMÁTICA GERATIVA E A GRAMÁTICA DE CONSTRUÇÕES ${ }^{1}$ SYNTHETIC CAUSATIVE CONSTRUCTION: A COMPARATIVE ANALYSIS BETWEEN GENERATIVE GRAMMAR AND CONSTRUCTION GRAMMAR
}

\author{
Glenda Queiroz Milanio (UFMG)²
}

\begin{abstract}
RESUMO: O objetivo deste trabalho foi analisar comparativamente as causativas simples derivadas de cenários convencionalizados do inglês com as causativas sintéticas do português brasileiro (PB). Para realização dessa pesquisa, adotamos como quadro teórico a Teoria Gerativa (CHOMSKY, 1981,1999, 2002; RAPOSO, 1992; MIOTO, 2007; PYLKKÄNEN 2002, 2008; BLANCO 2010, 2011; SILVA, 2009 e MILANIO, 2014) e a Gramática de Construções (GOLDBERG, 1995). Em relação às propriedades semânticas dessas construções, identificamos que elas apresentam uma leitura ambígua de papel temático na posição de sujeito. Além disso, são formadas com verbos que possuem como propriedade semântica a necessidade de um instrumento artificial alienável, que possa ser transferido de um indivíduo para outro. Assim, assumimos que essas construções possuem um causado com traço [+ agentivo], que não é realizado fonologicamente, embora faça parte da estrutural argumental do verbo. Esse causado [+agentivo] apresenta uma interpretação arbitrária como sujeito indeterminado capaz de executar a ação verbal. Em relação às propriedades sintáticas, essas construções necessitam dos núcleos funcionais VoiceP e vPCAUSE, para possibilitarem as projeções dos argumentos causador e causado [+agentivo], respectivamente. Desse modo, essa análise translinguística possibilitou constatarmos que as causativas simples do inglês e as causativas sintéticas do PB compartilham propriedades sintáticas e semânticas.
\end{abstract}

PALAVRAS-CHAVE: Causativas simples. Causativas sintéticas. Teoria Gerativa e Gramática de Construções.

\begin{abstract}
The aim of this paper is to analyze comparatively the simple causative sentences derived from conventionalized scenarios from English with synthetic causative sentences from Brazilian Portuguese (BP). For this work, we adopted as theoretical framework the Generative Theory (Chomsky, 1981, 1999, 2002; Raposo, 1992; Mioto, 2007; Pylkkänen 2002 2008; Blanco 2010, 2011; Silva, 2009; Milanio, 2014) and the Construction Grammar (Goldberg, 1995). In relation to semantic properties of these constructions, we identified that they share an ambiguous reading of thematic role of the subject position. Moreover, these constructions are formed with verbs which have semantic properties that require alienable instruments that can be exchanged between individuals. Therefore, we assume that these constructions have a caused with the trace [+ agentive] that is not realized phonetically, although it is part of the argument structure of the verb. These caused [+agentive] have an arbitrary interpretation as an undetermined subject that is able to execute the verbal action. In relation to syntactic properties, these constructions require the functional cores VoiceP and vPCAUSE to enable the projection of cause and caused [agentive +] arguments, respectively. These crosslinguistic analysis enable us to see that simple causative sentence in English and causative synthetic sentences in Portuguese share syntactic and semantic properties.
\end{abstract}

KEYWORDS: Simple causative. Synthetic causative. Generative Theory and Construction Grammar.

\footnotetext{
${ }^{1}$ Gostaria de registrar o meu agradecimento à professora Sueli Coelho (FALE-UFMG) pelas valiosas contribuições, que possibilitaram a realização deste artigo.

${ }^{2}$ Doutoranda em Estudos Linguísticos pela UFMG. Mestre em Linguística pela mesma instituição. Especialista em Gramática da Língua Portuguesa pela PUCMinas. Atualmente, é professora do curso de Letras da FIBH. E-mail: glendamilanio@hotmail.com
} 


\section{Considerações Iniciais}

Este trabalho tem como objetivo analisar as causativas simples de acordo com o quadro teórico da Gramática de Construções (GC), no inglês, e as causativas sintéticas de acordo com o quadro teórico do Programa Minimalista, no Português Brasileiro (PB). Em inglês, sentenças como Chris cut her hair at the salon on University Avenue e She painted her house (Chris cortou o cabelo no salão de beleza na avenida da universidade e Ela pintou sua casa), geralmente, apresentam um profissional para realizar o evento. Em PB, sentenças como Mara cortou o cabelo, Pedro operou o pé e Caetano reformou o apartamento também requerem um causado intermediário, que não é realizado fonologicamente (ex. cabeleireiro, cirurgião e pedreiro). Diante disso, buscaremos analisar se essas sentenças sintéticas compartilham pontos em comum referentes à forma e ao significado em ambos os idiomas. Essa proposta poderá reforçar, por um lado, a concepção de pareamento formasignificado defendido pela GC e a ideia de empacotamento do causado intermediário (Goldberg, 1995) e, por outro lado, enfatizar a concepção de uma gramática gerativa universal, aumentando o poder de generalização. Nesse contexto, nossa hipótese é que essas sentenças, de algum modo, apresentam similaridades no PB e no inglês, podendo suas estruturas sintáticas e semânticas serem descritas mais detalhadamente. É importante ressaltar que não temos a pretensão de oferecer respostas conclusivas, muito menos de propor uma análise última das construções causativas, mas apenas de realizar uma análise exploratória, que possa ser aprofundada futuramente.

Goldberg (1995), embora apresente uma concepção de gramática baseada no uso, defende que as construções emergem do pareamento forma-significado, aspecto compartilhado pela gramática gerativa, apesar de esta compreender o pareamento da Forma Lógica (FL) com a Forma Fonológica (FF) (CHOMSKY, 1999). Partindo dessa premissa baseada no uso, Goldberg (1995) passa a examinar o padrão estrutural de construções, em inglês, propõe suas formas básicas, explicando como as derivações são instanciadas. Em relação às causativas simples, elas são derivadas de cenários convencionalizados, pois implicam em uma causa convencionalizada que envolve um causado intermediário. Em resumo, Goldberg (1995) considera as causativas como produtos da língua em uso, que emergem em determinados contextos pragmático-discursivos convencionalizados socialmente. Já, na perspectiva gerativista, as causativas são interpretadas como produtos da gramática, estruturadas por núcleos lexicais e funcionais, que independem do contexto pragmáticodiscursivo.

Embora nossa pesquisa não se apoie predominantemente na gramática gerativa, tentaremos descrever sua estrutura sintática a partir do Programa Minimalista, visando alcançar algumas 
generalizações. Pressupomos que construções causativas sintéticas apresentam similaridades em relação às causativas simples, em inglês, pois apresentam dois subeventos: o evento causador e o evento causado. Assumimos, para os dados do PB, que esse causado deve apresentar traço [+ agentivo] e, também, não ser realizado fonologicamente. Além disso, é importante destacar que as causativas sintéticas são bastante produtivas no PB (BITTENCOURT, 1995, 2001), por isso toda descrição poderá contribuir para a compreensão dessa estrutura. Nesse contexto, salientamos que, embora Goldberg (1995) tenha apresentado uma análise consistente, a autora não explica com detalhes as propriedades sintáticas e semânticas das causativas simples. Desse modo, estabelecendo interlocução entre o Programa Minimalista e a GC, poderemos avançar nos estudos das causativas sintéticas, sobretudo, no que diz respeito ao empacotamento do causado intermediário (GOLDBERG, 1995, p. 169).

Para o tratamento do fenômeno analisado, tomaremos como base os estudos de Goldberg (1995) sobre a GC e os pressupostos da Teoria Gerativa (CHOMSKY, 1981; MIOTO, 2007; RAPOSO, 1992), incluindo os desenvolvimentos recentes do Programa Minimalista (CHOMSKY, 1999, 2002; KRATZER, 1996; PYLKKÄNEN 2002, 2008; BLANCO 2010, 2011; SILVA, 2009 e MILANIO, 2014), buscando estabelecer as propriedades sintáticas e semânticas das causativas sintéticas, propondo uma abordagem comparativa e complementar. Por fim, a metodologia empregada, para a realização desta pesquisa, consistirá no levantamento de dados coletados de trabalhos realizados na literatura existente. Primeiramente, serão extraídas as sentenças formadas com verbos transitivos e que exprimem a causatividade, ou seja, as causativas sintéticas. Cada sentença já transcrita será analisada de modo comparativo, considerando os pressupostos teóricos da GC e da Teoria Gerativa.

\section{Referencial Teórico}

\subsection{A Construção de Movimento Causado}

Goldberg (1995) observa que a "Gramática de Construções é gerativa no sentido de que tenta explicar o número infinito de expressões que são permitidas pela gramática e durante a tentativa para dar conta do fato de que um número infinito de outras expressões é descartado ou não permitido" (GOLDBERG, 1995, p. 34 - Tradução nossa). ${ }^{3}$ Assim, a autora aprofunda os estudos da GC ao analisar sentenças básicas, em inglês, propondo que as construções são resultantes do pareamento

\footnotetext{
${ }^{3}$ Construction Grammar is generative in the sense that it tries to account for the infinite number of expressions that are allowed by the grammar while attempting to account for the fact that an infinite number of other expressions are ruled out or disallowed. (GOLDBERG, 1995, p. 34).
} 
forma-significado, independentemente dos verbos instanciados pela estrutura. Goldberg (1995) analisa o padrão estrutural de vários tipos de construções, como bitransitivas, movimento causado, resultativas, de movimento intransitivo, conativas, descrevendo os argumentos que estão presentes nessas sentenças. O sentido básico das construções analisadas por Goldberg (1995) para os dados, em inglês, são sumarizados da seguinte forma:

a) Construção Bitransitiva (X CAUSA Y RECEBER Z)

$\begin{array}{llll}\text { SUJ } & \mathrm{V} & \mathrm{OBJ}_{1} & \mathrm{OBJ}_{2}\end{array}$

Pedro enviou uma carta para Ana

b) Construção de Movimento Causado (X CAUSA Y MOVER-SE PARA Z)

SUJ $\quad \mathrm{V} \quad \mathrm{OBJ}_{1} \quad \mathrm{OBJ}_{2}$

Pedro empurrou o gato da cozinha

c) Construção Resultativa $\quad \rightarrow \quad$ (X CAUSA Y TORNAR-SE Z)

SUJ $\quad \mathrm{V} \quad$ OBJ $\quad$ (PREDICATIVO) $^{4}$

Pedro quebrou o copo

d) Construção de Movimento Intransitivo (X MOVE Y )

SUJ $\quad$ V

O pernilongo zumbia no quarto

e) Construção Conativa (X DIRECIONA AÇÃOY RECEBER Z)

SUJ V OBL

Pedro chutou para João

Na construção de Movimento Causado, Goldberg (1995) toma os seguintes exemplos para realização de sua análise:

1) They laughed the poor guy out of the room. (= (?) Eles riram o pobre rapaz para fora do quarto.)

2) Frank sneezed the tissue off the table. (= Frank espirrou o tecido para fora da mesa.)

3) Mary urged Bill into the house. (= (?) Maria convidou Bill para (dentro de) a casa.)

(Goldberg, 1995, p. 152)

\footnotetext{
${ }^{4} \mathrm{O}$ dado original é She kissed him unconscious, que seria algo como "Ela o beijou (deixando-o) inconsciente". Leite (2006) esclarece que os dados apresentados por Goldberg (1995) da construção resultativa, em inglês, não apresentam pares semelhantes em português, pois não é possível formar uma construção com predicado simples que expresse a mudança de estado.
} 
A autora explica que, nas sentenças acima, o argumento causador causa o argumento tema a se mover para ao longo de uma trajetória, que é descrita pelo sintagma direcional. Goldberg (1995) analisa outras construções que são identificadas como extensões do sentido básico desse tipo de estrutura como as sentenças, a seguir:

4) Joe kicked the dog into the bathroom. (= Joe chutou o cão para a casa de banho.)

$(\rightarrow$ He caused the dog to move into the bathroom.) (= Ele causou o cão mover-se para a casa de banho.)

Joe hit the ball across the field. (= Joe bateu a bola no campo.)

5) ( $\rightarrow$ He caused the ball to move across the Field.) (= Ele causou que a bola se deslocasse através do campo.)

(Goldberg, 1995, p. 153)

Segundo a autora, esse tipo de construção não é uma de derivação de tipo de sentenças existentes na gramática do inglês. Além disso, Goldberg (1995) destaca que os verbos kick e hit (chutar e bater) não são verbos causativos e que apresentam sentido inerente de movimento causado, quando isolados. Desse modo, ao analisar os dados, a autora adverte que a interpretação de movimento causado de sentenças como (1)-(5) não pode ser atribuída sistematicamente ao verbo ou a preposição ou a sua combinação. Para a autora, esse tipo de estrutura é uma construção que combina verbo e preposição direcional, resultando em uma interpretação por convenção particular. Goldberg (1995) propõe uma representação para explicitar como a construção de movimento causado é instanciada. Vejamos:

6) Construção de Movimento Causado

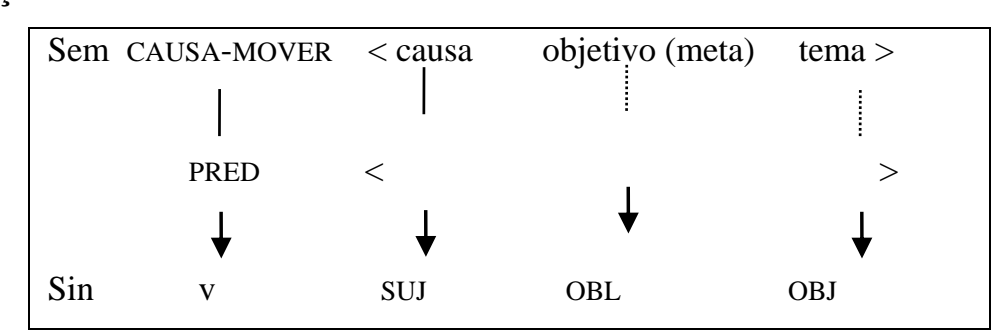

(Goldberg, 1995, p. 160)

Na representação básica da construção de movimento acima, o verbo expressa o significado de CAUSAR-MOVER. Em relação aos papéis semânticos, há um agente/causador, um alvo-objetivo e um tema. A autora apresenta outras possibilidades de construção de movimento causado, como as 
construções formadas com verbos que expressam força dinâmica, como em Sam allowed Bob out of the room e Sam let Bill into the room (?Sam permitidiu Bob para fora da sala e ?Sam deixou Bill para o quarto). Ao examinar essas construções, Goldberg (1995) considera como uma propriedade idiossincrática do inglês, pois essas sentenças não implicam um movimento real, mas metafórico. Além disso, a autora distingue outros tipos de estrutura de movimento causado em que expressa força dinâmica e um ato comunicativo, descrevendo como construções que possuem uma barreira interveniente como em Sam allowed him into the room e Sam permitted him into the house (?Sam permitiu-lhe para o quarto e ?Sam permitiu-lhe entrar na casa). Para a autora, nesses dois exemplos, não há uma decisão cognitiva de o objeto ser interpretado como um tema, pois o movimento real não é instanciado pela construção.

Goldberg (1995) elenca várias formas de construções de movimento causado, em inglês, propondo generalizações e apontando restrições semânticas e aparentes idiossincrasias, mas, em linhas gerais, considera que essas construções possuem um agente que causa, diretamente, um tema a se mover para outro local, podendo ser real ou metafórico. Entre os dados analisados pela autora, destacaremos uma forma de construção de movimento causado que Goldberg (1995) identifica como construções simples que envolvem cenários convencionalizados. Goldberg (1995, p. 168-167), baseada em Shibatani (1973), defende que há construções “que são convencionalmente realizadas de uma forma particular que podem ser expressas como causativas simples, sendo a causação indireta na medida em que existe de fato um causado intermediário." (tradução nossa) ${ }^{5}$. Vejamos:

7) The invalid owner ran his favorite horse (in the race).

8) Chris cut her hair at the salon on University Avenue.

9) She painted her house, (when in fact the painters did the painting)

10) Farmer Joe grew those grape vines. ${ }^{6}$

(GOLDBERG, 1995, p. 169)

Segundo Goldberg (1995), trata-se de um cenário convencional, pois é esperado que eventos como cortar cabelo, pintar casa, por exemplo, sejam realizados por profissionais. A autora identifica esse tipo de construção como uma causativa simples derivada de cenários convencionalizados,

\footnotetext{
5 "activitieswhich are conventionally accomplished in a particular way may be expressed as simple causatives, even when the causation is indirect insofar as there is in actuality an intermediate cause."

$6 \quad 7)$ O proprietário inválido correu seu cavalo favorito (na corrida).

8) Chris cortou o cabelo no salão de beleza na avenida da universidade.

9) Ela pintou a casa dela (quando, na verdade, os pintores fizeram a pintura)

10) O fazendeiro Joe cresceu essas videiras.
} 
envolvendo uma causação intermediária. Goldberg (1995) considera que essas estruturas expressam cenários convencionalizados, parecendo ser cognitivamente "empacotados", permitindo que a estrutura interna (causação intermediária) seja ignorada. Desse modo, Goldberg (1995) avalia que construções as quais expressam movimento causado indiretamente, ainda que de modo convencionalizado, sejam admissíveis como construção de movimento causado. Nesse contexto, a autora postula a generalização, o qual prevê "Cenários convencionalizados podem ser cognitivamente empacotados como um único evento, mesmo se existir uma causa interveniente" (GOLDBERG, 1995, p. 169 - tradução nossa ${ }^{7}$ ). No entanto, a autora não descreve esse processo de empacotamento, tampouco as propriedades sintáticas e as semânticas dessa construção.

\subsection{As causativas do Português Brasileiro}

Bittencourt (1995, 2001), com base em vertentes teóricas distintas, como Gramática Tradicional, Teoria Gerativa e, sobretudo, trabalhos funcionalistas (SHIBATANI 1975, 1976 e GIVÓN, 1975 e 1990), apresenta uma taxonomia para sentenças causativas. Bittencourt (1995), apoiando-se na análise de Shibatani (1976), compreende que o processo causativo expressa dois eventos, que ocorrem em momentos distintos: o evento causador ocorre num primeiro momento ( $\mathrm{t}_{1}$ ), já o evento causado ocorre num segundo momento (t2). Esse processo pode ser interpretado como uma forma correspondente à construção de movimento causado, proposta por Goldberg (1995), que apresenta a seguinte forma: [X CAUSA Y MOVER-SE PARA Z].

Ao descrever os dados do PB, Bittencourt $(1995,2001)$ descreve três estruturas básicas: as sentenças causativas analíticas, as semianalíticas e as sintéticas. As causativas analíticas, segundo a autora, possuem necessariamente um verbo causativo como mandar, fazer, deixar, seguido de uma oração completiva (ex.: João fez (com) que Maria varresse a casa). Segundo Bittencourt (1995, 2001), as causativas semianalíticas também possuem duas orações, uma com verbo causativo e outra oração completiva. Entretanto, a autora ressalta que, nesse tipo de causativa, o causado, geralmente, é expresso por um oblíquo, estabelecendo uma relação mais estreita entre a oração principal e o predicado causativo (ex.: João nos fez varrer a casa/João te fez varrer a casa). Por fim, Bittencourt $(1995,2001)$ apresenta a causativa sintética, cuja estrutura não possui um verbo necessariamente causativo. A autora esclarece que esse tipo de estrutura pode ser formado a partir de verbos intransitivos (ex.: A mãe correu os meninos da sala) e verbos transitivos (ex.: Maria fez as unhas pela manicure/ João consertou o carro pelo mecânico).

\footnotetext{
${ }^{7}$ Conventionalized scenarios can be cognitively packaged as a single event even if an intervening cause exists.
} 
Silva (2009) parte da pesquisa de Bittencourt (1995, 2001), em relação às sentenças causativas sintéticas, analisando as estruturas formadas a partir de verbos transitivos e intransitivos. Com base na teoria semântica (CANÇADO, 2003; 2006) e na Teoria Gerativa (CHOMSKY, 1999; HALE \& KEYSER, 1993; 1998), a autora defende que as causativas sintéticas formadas com verbos transitivos requerem um sintagma preposicional (SP) para licenciá-las:

11) a. A Luma de Oliveira fez sua fantasia de madrinha da bateria pelas costureiras da própria escola

b. Eu consertei o carro por aquele mecânico de nome maluco. ${ }^{8}$

(SILVA, 2009, p. 103)

A autora explica que o SP tem a função de introduzir o causado, isto é, costureiras e mecânico, respectivamente, que são os responsáveis por executar a ação expressa pelo verbo transitivo tanto em (11a) quanto em (11b). Além disso, Silva (2009) argumenta que o SP permite que as causativas sintéticas sejam licenciadas, pois é a preposição que possibilita a valoração do Caso abstrato ao terceiro argumento. Milanio (2014), ao reanalisar as causativas sintéticas com base nos desenvolvimentos recentes do Programa Minimalista (CHOMSKY, 1999, PYLKKÄNEN, 2002, 2008; BLANCO, 2010, 2011), propõe que essas sentenças não exigem o SP para licenciar o terceiro argumento. Por exemplo:
12) a. Mara cortou o cabelo.
b. Pedro operou o pé.
c. Caetano reformou o apartamento.
d. José consertou o carro.
e. Tereza pintou a casa.
f. O fazendeiro inseminou as vacas.
g. Ester transplantou a córnea.
h. Artur podou a grama.

(MILANIO, 2014, p. 70)

\footnotetext{
${ }^{8}$ Cabe descartar que a preposição pelas e por presentes nos dados (11a) e (11b), respectivamente, se substituídas pela preposição com, parece formar sentenças mais aceitáveis no PB. Por exemplo, “A Luma de Oliveira fez sua fantasia de madrinha da bateria com as costureiras da própria escola" e "Eu consertei o carro com aquele mecânico de nome maluco.
} 
Nesse contexto, no que diz respeito à estrutura sintática das causativas sintéticas, assumimos que essas sentenças (12a)-(12h) possuem uma estrutura subjacente formada por um vP fásico, ou seja, um VP mais articulado, que possibilita a abertura de mais projeções (LARSON, 1988). Em relação às propriedades semânticas das causativas sintéticas, em nossa análise (MILANIO, 2014), com base em Levin (1993) e Levin e Rappaport (1995), assumimos que essas sentenças são formadas por verbos transitivos (cortar, operar, reformar, consertar, etc.), que possuem como propriedade semântica a necessidade de um instrumento para execução da ação. Por exemplo, o verbo cortar requer um instrumento cortante, como tesoura, lâmina e estilete, para a realização da ação, já o verbo operar requer instrumentos cirúrgicos, como bisturi, pinça, tesoura, etc. Por fim, o verbo reformar requer instrumentos da construção civil, como marreta, martelo, talhadeira, etc. Para analisarmos as propriedades dos verbos, tomamos como base a visão global da arquitetura cognitiva (STILLINGS, et. al., 1995), fundamentada na tese da modularidade, para distinguirmos os verbos que permitem a construção de sentenças causativas formadas a partir de verbos transitivos. Desse modo, identificamos três classes de verbos, sendo apenas uma categoria específica de verbos motores que permitem tais construções causativas. Vejamos:

Verbos sensoriais $\rightarrow$ relacionados ao sistema sensorial, como ver, ouvir, enxergar, cheirar. As ações descritas por esses verbos requerem partes específicas do corpo, como olhos, ouvidos, isto é, instrumentos biológicos inalienáveis.

Verbos de processamento $\rightarrow$ relacionados ao sistema central, como pensar, refletir, memorizar, amar, lembrar. Esses verbos também dependem de instrumentos biológicos inalienáveis (ex.: diferentes regiões cerebrais).

Verbos motores $\rightarrow$ nessa categoria há duas subclasses:

Primeira ordem: verbos relacionados ao sistema motor, como beijar, arranhar e chutar. Esses verbos também dependem de instrumentos biológicos inalienáveis (ex.: boca, unha, pés).

Segunda ordem: relacionados ao sistema motor, como cortar, reformar e operar. Esses verbos dependem de instrumentos artificiais alienáveis (ex.: tesoura, lâmina, bisturi, pinça, marreta, martelo, etc.).

Baseada na visão global da arquitetura cognitiva (STILLINGS, et. al., 1995), Milanio (2014) percebeu que apenas os verbos motores de segunda ordem licenciam construções causativas sintéticas formadas a partir de verbos transitivos. Esses verbos requerem um instrumento, assim 
como analisado por Levin (1993) e Levin e Rappaport (1995), entretanto ele deve ser um instrumento alienável, ou seja, passivo de ser transferido de posse entre indivíduos. A sentença João cortou o cabelo é causativa, porque o verbo cortar requer necessariamente instrumentos (ex.: tesoura), que, além de ser indispensável à realização da ação, pode ser alienável. Afinal, é absolutamente possível uma pessoa cortar o cabelo de outro, deslocando as tesouras, aparadores e pentes de um agente para outro, o que explicaria o aspecto ambíguo das causativas sintéticas. Entretanto, a sentença Fernanda beijou Pedro (com a boca), embora tenha um verbo motor, requer um instrumento biológico (no caso, a boca), que, apesar de ser indispensável à realização da ação, não pode ser alienado, ou seja, transferido de posse entre indivíduos. Em resumo, Milanio (2014, p. 39-40) propôs um teste que possibilita julgar e decidir, com maior segurança, quando uma sentença é causativa sintética formada a partir de verbo transitivo.

\section{A Causativa Sintética}

Nesta seção, examinaremos as causativas simples proposta por Goldberg (1995), comparando ao tratamento adotado por Milanio (2014), ao analisar as causativas sintéticas do PB.

\subsection{Causativas Simples versus Construções Causativas Sintéticas}

Goldberg (1995) explica que as causativas simples, que envolvem cenários convencionalizados, não expressam o causado intermediário, mas ele pode ser recuperado cognitivamente, como nos exemplos (7)-(10), apresentados na seção anterior. A autora explica que, nessas construções, ocorre o "empacotamento" cognitivo do causado intermediário como um único evento. Assim, para a autora, nas construções (7)-(10), o causado intermediário está implícito. Goldberg (1995) ainda destaca que, nas sentenças (8) e (9), a ação de verbos como cut e paint (cortar e pintar) são diretamente relacionadas a um profissional capaz de executar tais ações. Desse modo, para a autora, a causatividade da construção não está relacionada ao verbo que é instanciado pela causativa simples, mas o significado da causatividade emerge da construção como um todo. Assim, o significado desse tipo de construção não é obtido somente pela forma, ou seja, por meio dos termos que a compõem, já que para sua compreensão o falante deve ter o conhecimento convecionalizado sobre os papéis semânticos dos argumentos que estão envolvidos no evento, isto é, dos cenários convencionalizados. Por isso, podem ser recuperados cognitivamente. É importante destacar que Goldberg (1995) defende que as construções são resultantes do pareamento forma-significado, 
entretanto, a autora não deixa claro qual é a forma da construção de cenário convencionalizado, pois, se há o empacotamento, é necessário explicar a forma dessa construção.

Considerando as propriedades sintáticas das causativas simples, vamos assumir que sentenças como Chris cut her hair at the salon on University Avenue e She painted her house podem ser compreendidas como causativas sintéticas tal como os dados listados em (12). Desse modo, identificaremos essas construções como semelhantes à Mara cortou o cabelo, Pedro operou o pé e Caetano reformou o apartamento, sendo classificadas como causativas sintéticas. Embora essas sentenças não apresentem verbos causativos, elas expressam dois subeventos: o evento causador e o evento causado. O evento causado apresenta traço [+ agentivo], pois ele será o responsável executar as ações expressas como cortar, operar e reformar, porém ele não é realizado fonologicamente na estrutura sintética. Assim, para o licenciamento dessas construções, assumimos que o processo tratado como empacotamento por Goldberg (1995) é analisado como construções causativas sintéticas que apresentam uma estrutura subjacente. Em nossa análise, as causativas sintéticas são derivadas de causativas analíticas:

13) a. Mara fez $_{\mathrm{X}}$ cortar o $\left(\mathrm{seu}_{\mathrm{i}}\right)$ cabelo $\rightarrow$ Mara ${ }_{\mathrm{i}}$ cortou o $\left(\mathrm{seu}_{\mathrm{i}}\right)$ cabelo.

b. Pedroifez X operar $\left(\mathrm{seu}_{\mathrm{i}}\right)$ pé $\rightarrow$ Pedroi operou o $\left(\mathrm{seu}_{\mathrm{i}}\right)$ pé.

c. Caetanoi fez $\mathrm{X}$ reformarn $\left(\mathrm{seu}_{\mathrm{i}}\right)$ apartamento $\rightarrow$ Caetanoi reformou o $\left(\mathrm{seu}_{\mathrm{i}}\right)$ apartamento.

Sintaticamente, essas sentenças são licenciadas, pois possuem dois vPs, um para projetar o verbo leve e outro para o verbo transitivo. Partindo da pesquisa translinguística de Pylkkänen, (2002, 2008) e de Blanco, (2010, 2011), nas quais analisam dados do finlandês, do inglês, do japonês e do espanhol, passamos a considerar que as causativas sintéticas apresentam os núcleos funcionais VoiceP, para projetar o argumento externo (o causador), e vCAUSE, para projetar o verbo leve (fazer) das causativas do PB. O núcleo Voice, proposto inicialmente por Kratzer (1996), constitui de uma projeção realizada acima da projeção máxima (VP), que tem como função introduzir o argumento externo de verbos transitivos. Pylkkänen $(2002,2008)$, ao reanalisar o núcleo VoiceP, argumenta que toda estrutura causativa possui dois núcleos funcionais: VoiceP e núcleo CAUSE. Nessa perspectiva, VoiceP projeta o agente do evento e núcleo CAUSE introduz o evento da causação. Além disso, essas estruturas 
apresentam um DP (Determiner Phrase - Sintagma Determinante) pro $^{\text {arb9 }}$ para abrigar o argumento que ocupa o sujeito da sentença encaixada. Vejamos:

14) a. Mara cortou o cabelo
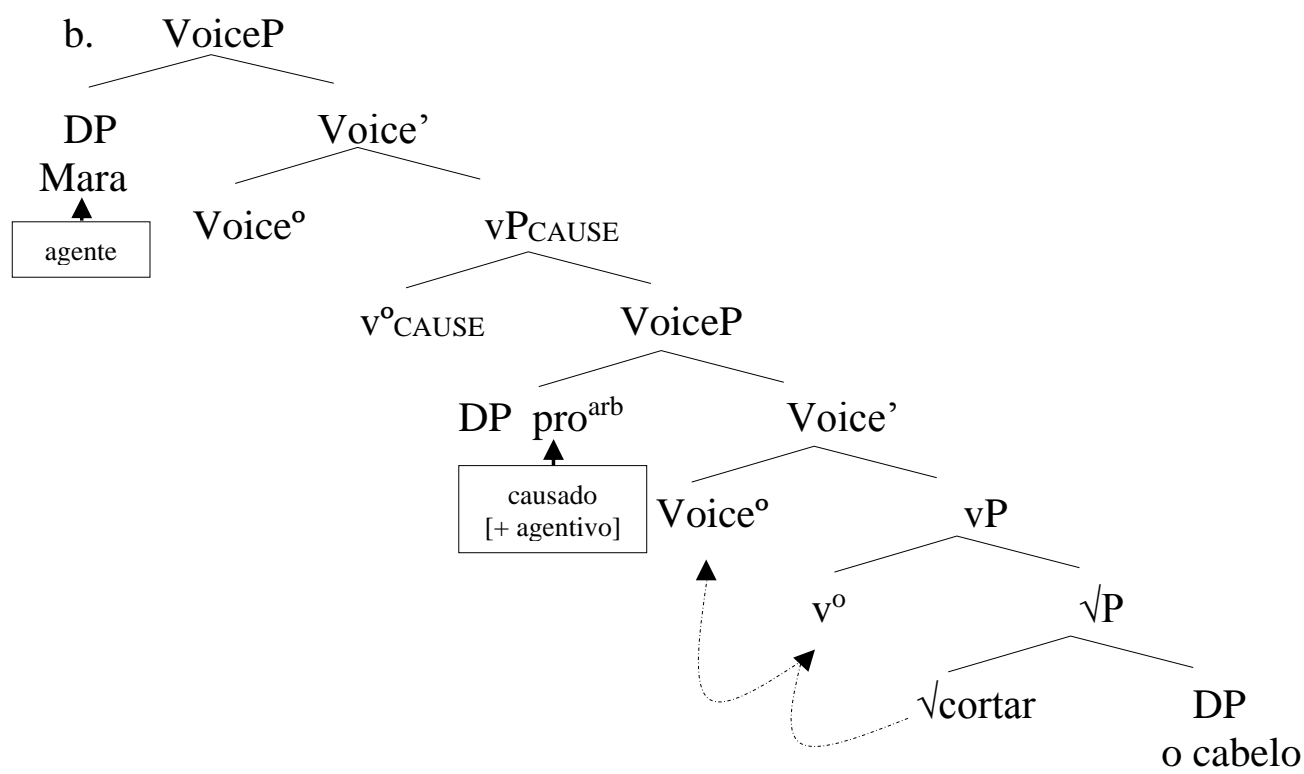

(MILANIO, 2014, p. 74)

Conforme pode ser observado, na representação, o VoiceP superior é necessário para projetar o argumento externo da oração principal, já o vPCAUSE é responsável por projetar o verbo leve fazer. O VoiceP interno tem função de projetar o DP pro ${ }^{\text {arb }}$, isto é, pode projetar um sujeito indeterminado que, semanticamente, possa ser responsável por executar o evento causado, como cortar, operar e reformar. Essa representação sintática mais articulada permite a abertura de mais projeções, possibilitando abrigar o verbo leve fazer e o argumento que ocupa a posição de sujeito da sentença encaixada, tornando possível a realização de todos os argumentos necessários para a construção. Essa derivação também nos possibilita explicar que o DP pro ${ }^{\text {arb }}$, como é interpretado como sujeito da sentença encaixada, tem o caso nominativo valorado antes de spell-out e, por isso, ele ocorre na Forma Lógica (FL) e não precisa ser visível na FF (Forma Fonética), isso explica a omissão do causado intermediário, conforme a análise de Goldberg (1995). Assim, o que Goldberg (1995) analisa como empacotamento, assumimos que se trata de uma construção causativa sintética que é derivada de uma causativa analítica subjacente, sendo a interpretação dessa estrutura subjacente que possibilita compreender a construção como um todo. Por meio dessa representação,

\footnotetext{
${ }^{9}$ Segundo Duarte (1995), o pro ${ }^{\text {arb }}$ é uma categoria vazia pronominal, que faz referência a um sujeito indeterminado interpretado como o indivíduo, o cara, a pessoa, etc. Segundo a autora, nos dados do PB, esse elemento apresenta os traços semânticos [+animado] e [+genérico].
} 
torna-se possível depreender o pareamento da forma e do significado, embora Milanio (2014) tenha demonstrado que o julgamento das causativas sintéticas esteja condicionado aos traços verbais [+verbo motor, +instrumento alienável]. Consideramos a análise de Goldberg (1995) consistente, porém a autora não explica detalhadamente as propriedades sintáticas das causativas simples e quais são os traços semânticos que licenciam essa construção. Nesse contexto, adotamos a representação em (14) para evidenciar que há toda uma operação sintática que possibilita a formação dessa construção. Isso significa que não se trata apenas de empacotamento, pois é possível perceber que a interpretação como um único evento advém de uma estrutura mais complexa. Em outras palavras, o princípio da economia cognitiva parece, em termos diacrônicos, reduzir a frequência de construções complexas em busca de processamentos cognitivos mais simples, sendo o empacotamento, citado por Goldberg (1995), um exemplo dessa relação.

No que diz respeito aos traços semânticos das causativas sintéticas, assumimos que, para a realização dessas construções, o verbo transitivo que expressa o evento causado deve, necessariamente, ser um verbo motor de segunda ordem. Postulamos que esses verbos possuem uma restrição semântica que, só por meio de instrumentos alienáveis ações, como cortar, operar, pintar, reformar, costurar, etc., podem ser executadas. Milanio (2014) propõe um teste com cinco etapas ${ }^{10}$ para identificar se uma sentença é causativa sintética. Em linhas gerais, é necessário reconhecer que há ambiguidade em relação ao papel temático do argumento externo e se há um verbo motor de segunda ordem que requer um instrumento alienável para a realização do evento descrito pelo verbo transitivo. Retomemos os dados:
15) a. Mara cortou o cabelo
b. Pedro operou o pé
c. Caetano reformou o apartamento
d. José consertou o carro
e. Tereza pintou a casa
f. $\mathrm{O}$ fazendeiro inseminou as vacas
g. Ester transplantou a córnea
h. Artur podou a grama

\footnotetext{
${ }^{10}$ Primeira etapa - Verificar a transitividade do verbo;

Segunda etapa - Verificar se o verbo está associado ao sistema sensorial, ao processamento ou ao motor; Terceira etapa - Identificar se há ambiguidade de papel temático;

Quarta etapa - Verificar se há a necessidade da utilização de instrumento artificial (tesoura, bisturi, alicate, etc.) para a realização da ação;

Quinta etapa - Conferir se o instrumento é alienável, ou seja, se ele pode ser deslocado de uma pessoa para outra.
} 
$\mathrm{O}$ argumento externo de todas as sentenças acima pode ser inicialmente interpretado como o executor da ação expressa pelos verbos transitivos cortar, operar, reformar, etc. Porém, esse argumento também pode ser compreendido como um causador do evento que será executado por um terceiro, como um cabeleireiro, um médico, um pedreiro, etc. Essa leitura ambígua, identificada como ambiguidade de papéis temáticos (CANÇADO, 2008), pode ser verificada se tomarmos os seguintes exemplos:

16) a. A cabeleireira cortou o cabelo da Mara.

b. O médico operou o pé do Pedro.

c. O pedreiro reformou o apartamento do Caetano.

Nas sentenças acima, não há leitura ambígua, pois os argumentos que preenchem a posição de sujeito são os agentes das ações de cortar, operar e reformar, respectivamente. Já, nas sentenças (15a)-(15h), a princípio, há uma leitura ambígua, pois o argumento externo pode tanto ser o agente como o desencadeador do evento de cortar, operar e reformar, etc. Essa ambiguidade em relação ao papel temático do sujeito da sentença é, portanto, um traço da sentença causativa sintética. Outro traço fundamental é que o verbo instanciado pela construção seja um verbo motor de segunda ordem. Isso significa que para a realização das ações de como cortar, operar, pintar, reformar, costurar, etc. é imprescindível instrumentos artificiais alienáveis como tesoura, bisturi, pinça, pincel, alicate, martelo, etc. Essa restrição semântica ocorre em função do instrumento artificial alienável poder ter sua posse transferida, ou seja, tesoura, bisturi, pinça, pincel, alicate, martelo podem ser passados de um indivíduo para outro. Esse traço semântico torna possível a leitura de que um indivíduo possa executar a função no lugar de outro. Essa relação fica clara ao tomarmos verbos sensoriais, verbos de processamento e verbos motores de primeira ordem, pois com verbos como ver, pensar, beijar, etc. não é possível um indivíduo executar essas ações no lugar de outra pessoa. Assim, a leitura ambígua em relação ao papel temático do argumento externo e a restrição semântica dos verbos são propriedades fundamentais para o licenciamento e a interpretação das sentenças causativas sintéticas. É válido ressaltar que o instrumento artificial alienável pode ou não ser realizado fonologicamente, caso seja realizado, ele virá em posição de adjunção ao vP mais baixo na representação arbórea, como, por exemplo, Mara cortou o cabelo com navalha. Em síntese, estamos admitindo que as causativas dependem, sobretudo, de propriedades verbais e não de construções como defendido por Goldberg (1995). 
Diante do exposto, consideramos que o trabalho de Goldberg (1995) traz um avanço em relação à análise das causativas sintéticas. No entanto, não vamos compartilhar a visão de que as causativas simples são derivadas de cenários convecionalizados, pois, para a autora, a interpretação dessas construções depende do uso convencionalizado, em que o causado intermediário não é expresso e a construção pode ser empacotada como um único evento. Essa interpretação condiciona, em nossa opinião, as causativas ao âmbito da pragmática, mas como mostramos tratam-se de aspectos de natureza sintática e semântica. Portanto, vamos assumir que para a realização dessa construção, não se trata de um fenômeno de convencionalização, que possibilita o empacotamento, uma vez que esse processo considera relações extralinguísticas, como o contexto discursivo, pragmático, entre outros aspectos (VALLDUVÍ, 1992). Logo, assumimos que o licenciamento das causativas sintéticas não está relacionado a uma questão de convencionalização, mas a um processo de natureza gramatical que obedece ao princípio da economia cognitiva (MILANIO; FERREIRA, 2013). No entanto, não estamos defendendo uma visão divergente, mas sim complementar, pois analisamos que a convencionalização e o empacotamento, conforme postulados por Goldberg (1995), podem ser traduzidos por propriedades sintáticas e semânticas que licenciam as construções sintéticas.

\section{Considerações Finais}

Neste trabalho, buscamos comparar as causativas simples, propostas pela Gramática de Construções (GOLDBERG,1995), às construções causativas sintéticas, analisada pela Teoria Gerativa (BITTENCOURT, 1995, 2001; SILVA, 2009 e MILANIO, 2014). Consideramos o trabalho de Goldberg (1995) categórico para a análise de movimento causado, porém não compartilhamos a visão de que as causativas simples são licenciadas em função de um uso convencional (isto é, de um cenário convencionalizado), uma vez que tentamos explicitar as propriedades sintáticas e semânticas que possibilitam a formação dessas construções.

Defendemos que essas construções não emergem a partir do todo da estrutura, como propõe a gramática de construções (GOLDBERG, 1995), mas sim são estruturadas por meio de diferentes núcleos funcionais (PYLKKÄNEN 2002, 2008; BLANCO 2010, 2011). Adotamos os núcleos VoiceP e vCAUSE para explicarmos como as causativas sintéticas são projetadas sintaticamente, sendo essas propriedades extraídas de análises translinguísticas, como no inglês, no finlandês, no japonês e no espanhol (PYLKKÄNEN 2002, 2008; BLANCO 2010, 2011). Em nossa opinião, parece haver uma hierarquia da causação (MILANIO; FERREIRA, 2013) no que Goldberg (1995) identificou como 
"empacotamento", como se a situação causativa fosse um meio mais fácil de processamento, no qual causativas sintéticas originam-se de causativas analíticas.

Desse modo, ao tomarmos a premissa que as construções são pareamento forma-significado, conforme defendido por Goldberg (1995), refutamos que uma causativa simples seja analisada como um resultante de um processo de empacotamento como evento único, pois assumimos que se trata de uma construção derivada de uma construção causativa analítica. Além disso, assumimos que essas estruturas possuem argumentos que não são realizados fonologicamente, mas que fazem parte da estrutura argumental. Por exemplo, o causado intermediário que pode ser ignorado, para Goldberg (1995), tem função de executar o evento desencadeado. Esse causado tem traço [+ agentivo], trata-se de um argumento que não é realizado fonologicamente, mas sua interpretação é necessária para representar o sujeito indeterminado (DP pro ${ }^{\text {arb }}$ ), capaz de realizar o evento descrito pelo verbo transitivo. Nessa análise, as construções causativas sintéticas apresentam um causador responsável por desencadear o primeiro evento e um causado que tem a função de executar o segundo evento (causado). Em resumo, entendemos o pareamento forma-significado como expressão da gramática, não do uso, bem como da inter-relação entre os módulos fonológicos e semânticos.

Finalizando, essa análise translinguística possibilitou verificar que essas construções são aceitáveis tanto no inglês, quanto no português. Além disso, foi possível averiguar que as construções sintéticas compartilham forma e significado muito semelhantes nas duas línguas. Contudo, precisamos explorar ainda mais as propriedades sintáticas e semânticas dessas construções, desenvolvendo uma análise mais apurada. Essas questões poderão contribuir para estudos futuros.

\section{Referências}

ARRAIS, T. As construções causativas em português. In: Alfa. 29. São Paulo. p. 41-58, 1985.

BERNARDO, S.. Olha só: uma construção de movimento causado presumido. Linguístico (PPGL/UFRJ), v. 2, p. 255-270, 2007.

BITTENCOURT, V. de O. Da Expressão da Causatividade no Português do Brasil: uma Viagem no Túnel do Tempo. (1995). Tese (Doutorado). Pontifícia Universidade Católica de São Paulo, 1995.

- Causativas lexicais no português do Brasil: perfil morfossintático, semântico e funcional-discursivo. In: DECAT, M. B. N. et. al. Aspectos da Gramática do Português: uma abordagem funcionalista. Campinas: Mercado de Letras. 2001. p. 167-232.

BLANCO, M. T. Contrasting Causatives: A Minimalist Approach. 2010. 412 F. Tese (Doctor of Philosophy). The University Of Arizona: Tucson, 2010. 
2011.

. Causatives in Minimalism. Amsterdam / Philadelphia: John Benjamins Publishing,

CANÇADO, M. Manual de Semântica. Belo Horizonte: Editora UFMG, 2008.

CHOMSKY, N. O Programa Minimalista. Tradução: Eduardo Raposo. Lisboa: Caminho, 1999.

. Minimalist inquiries: The framework. In: Step by step: Essays on Minimalist Syntax in Honor of Howard Lasnik, Roger Martin, David Michaels \& Juan Uriagereka (eds). Cambridge MA: The MIT Press. 2000. p 89-155.

FERRARI, L. Gramática de Construções. In: Introdução à Linguística Cognitiva. São Paulo: Contexto, 2011. p. 129-146.

GOLDBERG. A. A Construction Grammar Approach to Argument Structure. Chicago: The University of Chicago Press.1995.

KRATZER, A. Severing the External Argument from its Verb. In: Rooryck, J.; Zaring, L. eds., Phrase Structure and the Lexicon. Dodrecht: Kluwer Academic Publishers, 1996, p. 109-137.

LARSON, R. On the double object construction. Linguistic Inquiry, v. 19, p. 335-391. 1988.

LEITE, M. A. Resultatividade: um estudo das construções resultativas em Português. (2006) 153f. Tese (Doutorado). Programa de Pós-Graduação em Letras Vernáculas da Universidade Federal do Rio de Janeiro (UFRJ): Rio de Janeiro, 2006.

LEVIN, B. English Verb Classes and Alternations: A Preliminary Investigation. Chicago: University of Chicago Press, 1993.

.; RAPPAPORT HOVAV, M. Unaccusativity: at the syntax lexical semantics interface.

Cambridge: MIT Press, 1995.

MILANIO, G. A. Q. As causativas sintéticas do Português Brasileiro de acordo com o modelo minimalista. (2014) 94f. Dissertação (Mestrado). UFMG - Programa de Pós-graduação em Estudos Linguísticos/POSLIN: Belo Horizonte, 2014.

.; FERREIRA, W. A. A interferência da polissemia do verbo fazer em sentenças causativas: uma análise linguística e cognitiva. In: Signo. Santa Cruz do Sul, v. 38., n. 65. p. 98-113, 2013.

MIOTO, C. et al.. Novo Manual de Sintaxe. Florianópolis, Insular, 2007.

PYLKKÄNEN, L. Introducing Arguments. 2002. 137 f. Tese (Doctor of Philosophy) Massachusetts Institute of Technology: Cambridge, 2002.

Introducing Arguments. Cambridge: The MIT Press, 2008.

RAPOSO, E. P. Teoria da Gramática: A faculdade da Linguagem. Caminho: Lisboa, 1992. 
SHIBATANI, M . Causativization. In: SHIBATANI , M. (Ed.) Syntax and Semantics. Vol. 5. New York: Academic Press. 1976, p. 239-294.

. et. al. The Grammar of Causation and Interpersonal Manipulation. SHIBATANI, M (Ed.). Amsterdam / Philadelphia: John Benjamins Publishing Company, 2002.

SILVA, Y. R. B. As Causativas Sintéticas no Português do Brasil: Novas Evidências a Favor da Estrutura Bipartida do VP. (2009) 134f. Dissertação (Mestrado). UFMG - Programa de Pósgraduação em Estudos Linguísticos/POSLIN: Belo Horizonte, 2009.

STILlINGS, N. A.; WEISLER, S. E.; CHASE, C. H.; FEINSTEIN, M. H.; GARFIELD, J. L.; RISSLAND, E; L.. Cognitive Science: An Introduction. Second Edition. Cambridge, Massachusetts, London, England: Bradford Book-The MIT Press, 1995.

VALLDUVÍ, E. The Informational Component. New York: Garland. 1992.

ZIEGELER, D.; LEE, S. A metonymic analysis of Singaporean and Malaysian English causative constructions. In: PANTHER, K.; THORNBURG, L. L.; BARCELONA, A. Metonymy and metaphor in grammar. Amsterdam: John Benjamins, 2009. p. 291-322. 